Original research article

\title{
Mobile phones, batteries and power consumption: An analysis of social practices in Portugal
}

\author{
Ana Horta*, Susana Fonseca, Mónica Truninger, Nélia Nobre, Augusta Correia \\ University of Lisbon, Institute of Social Sciences, Portugal, Rua Prof. Aníbal de Bettencourt, 9, 1600-189 Lisbon Portugal
}

\section{A R T I C L E I N F O}

\section{Article history:}

Received 2 April 2015

Received in revised form

27 November 2015

Accepted 30 November 2015

Available online xxx

\section{Keywords:}

Energy sociology

Theories of practice

Distributed agency

Information and communication

technologies

Youth

Everyday life

\begin{abstract}
A B S T R A C T
The article examines how social practices of charging and managing the power of mobile phones are formed. The usefulness of the concept of distributed agency as a tool for the understanding of the dimensions that constitute social practices related to energy consumption is explored. Based on findings from interviews and a survey conducted with adolescents, three moments in the formation of these practices are identified: emergence of elementary battery use, acceleration of rhythm and establishment of links, and normalization. The article provides empirical evidence of the distributed agency of bodies, objects, and socio-cultural contexts in the development of these practices.
\end{abstract}

(C) 2015 Elsevier Ltd. All rights reserved.

\section{Introduction}

Mobile communication devices have spread rapidly and are becoming ubiquitous in everyday life. Despite uneven dissemination across the world, mobile telephone subscriptions have nearly reached the number of people on Earth [30]. Concomitantly, the overall energy consumption related to mobile phones has been growing [68]. It is estimated that the global $\mathrm{CO}_{2}$ emissions of mobile communications may almost triple between 2007 and 2020 [16]. A growing body of literature points out several factors as contributors to the rise of energy consumption related to mobile phones: increasing ownership and rapid replacement of older devices (stimulated by marketing strategies and product design); growing data traffic due to the common use of applications relying on the internet (web browsing, gaming, and especially video streaming, requiring powerful servers and data centers which need cooling); an increasing number of sites of mobile network infrastructure; wide and bright screens; inefficiency during the charging process; standby consumption of battery chargers; among others [8,68,25,41,59].

\footnotetext{
* Corresponding author.

E-mail addresses: ana.horta@ics.ulisboa.pt

(A. Horta), susana.fonseca@ics.ulisboa.pt (S. Fonseca),

monica.truninger@ics.ulisboa.pt (M. Truninger),nobrenelia@gmail.com (N. Nobre), augusta.correia@ics.ulisboa.pt (A. Correia).
}

Notwithstanding recent efficiency improvements to the battery chargers of mobile phones, these still have energy losses, which are increased by the fact that chargers still consume energy when they are left plugged into the grid [28,25].

Few studies focus on human-battery interaction, and these indicate that the way users relate to mobile phones may increase the energy consumption associated with these devices [3,26]. Moreover, Rahmati and Zhong [45] observed that power-saving settings of mobile phones are designed in ways that are hard for users to employ them. These studies have been conducted mostly in the field of computer engineering, often trying to assess models of increasing energy efficiency (mainly by providing more information to users). Thus, they do not offer analysis of how the power requirement of mobile phone batteries is entangled in everyday life practices.

Some studies have analyzed sociological aspects of energy consumption related to the use of information and communication technologies $[20,21,15,31,48,47,13,49,50,44,11]$. These studies provide insightful and valuable contributions to the analysis of energy consumption related to these technologies. However, none of these studies focuses exclusively on mobile phones.

The energy consumption involved in charging the batteries of mobile phones is a small contributor to the global challenges related to the current energy transition. However, analysis of the social practices of charging and managing the batteries of mobile 
phones sheds light on how these energy-using technologies are embedded in society. This analysis may therefore contribute to the understanding of energy as an "ingredient" of the everyday life practices of which societies are composed [57].

From this perspective, this article seeks to analyze the energy consumption related to mobile phone use by focusing on the practices of charging and managing the power of mobile phones. With this purpose in mind we draw on theories of practice $[46,63,64,56,57]$ and explore the concept of distributed agency $[65,66,51]$ as a useful tool for the understanding of the dimensions that constitute these social practices.

The pervasiveness and embeddedness of mobile phones in young people's daily lives make adolescents a preferential group of practitioners for analysis of the practices of charging and managing mobile phone batteries. Indeed, the adoption and use of mobile phones are higher among young people [38,39]. In recent years social science has produced knowledge of several aspects of the diffusion and appropriation of mobile phones by young people (e.g., $[35,60,14,18])$. However, the topic of mobile phones' energy consumption has generally been overlooked. In a recent review of research on young people's use of mobile phones, Haddon [24] observed that most studies have focused on their relations with parents and peers. Regarding the relationships between parents and their children, research has shown that the former usually provide mobile phones to the latter and subsequently finance their use. Although this is sometimes a way for parents to monitor children, the mobile phone may also be a means whereby children achieve some privacy and autonomy [24]. On the subject of the relations between peers, research has highlighted the symbolic dimension of mobile phones in young people's presentation of self, as these devices are often used as indicators of trendiness and popularity [24]. Research has also pointed to youth's openness to new technologies, pioneering uses and ability to appropriate mobile phones for their own purposes [9]. Our study adds to this literature by explaining how adolescents are recruited to the practices of charging and managing the power of mobile phones. In doing so, we contribute to the understanding of energy consumption in the everyday life of adolescents.

In the following we present a brief introduction to the theories of practice, paying more attention to the three dimensions highlighted by the concept of distributed agency (bodies, objects and socio-cultural contexts) and how they constitute social practices. After presenting the materials and methods used in our study, we analyze the emergence and normalization of the practices of charging and managing mobile phone batteries among adolescents.

\section{Understanding practices related to energy consumption}

A key idea in the development of the sociology of energy is the acknowledgement of the relevance of understanding mundane consumption. Unlike other things that are consumed in a clearly visible way, energy use is mostly invisible, and derives from services, such as heating, lighting, cleaning $[67,54]$ or connectivity with others. Indeed, electricity and other forms of energy "are essential but, if brought to mind at all, tend to be considered subordinate, instrumental to a more meaningful activity" [23,pp. 4-5]. In the "mobile network society" [9], more and more objects of everyday life consume energy. This consumption is often surreptitious and imperceptible. In order to understand energy consumption, attention should therefore be given to embodied habits, routines, and modes of use of energy services. How these services become configured and appropriated at a societal level as normal practice should thus be analyzed [54]. In this thread, social conventions have a strong influence on the demand for energy services, but as these services are provided by technologies, attention should also be given to material contexts and conditions of use, such as users' competences [27].

In this perspective, theories of practice provide a valuable background for the analysis of energy consumption. In spite of being rather heterogeneous and with multiple versions, it can be said that practice theory (shorthand for theories of practice henceforth) is based on the work of Giddens [19] and Bourdieu [5], as recently revived with the contributions of Schatzki and Reckwitz [52], [46] and, in particular within consumption studies, of Warde [63], and Shove et al. [56], among others. In our account we are also especially drawing on Wilhite [66].

Practice theory enables us to understand the complexity of inconspicuous routines by examining how combinations of elements such as materials (things, technologies), competences (skills, know-how) and meanings (conventions, ideas, aspirations), coevolve, and how these are enacted in the form of patterns of practices, which are carried out by individuals in the course of their normal everyday life and embedded in social dynamics and historical and material contexts [56]. According to Reckwitz [46,p. 249], a practice "is a routinized type of behavior which consists of several elements, interconnected to one another: forms of bodily activities, forms of mental activities, 'things' and their use, a background knowledge in the form of understanding, know-how, states of emotion and motivational knowledge." It seems worthwhile to highlight some of these elements, namely by referring to the fact that practices are thus seen as skillful movements of bodies, or "routinized bodily performances", as in the case of walking a dog, cooking or talking on the phone; moreover, these performances require "certain routinized ways of understanding the world, of desiring something, of knowing how to do something", and are enabled or limited by things [46,pp. 251-252]. Despite the acknowledgement of the relevance of these elements, the roles played by bodies and things in habits and routines still need clarification [64].

In line with this theoretical framework, energy consumption should not be considered as "something performed by individuals" but a "result of the interaction between things, people, knowledge, and social contexts" [66,p. 67]. This standpoint can be expanded further through the concept of distributed agency [66], which seems to condense some of the major threads of practice theory. Understanding agency as capacity to influence acts ([40] cit. in [66]), distributed agency means that the capacity of forming a particular practice is shared by agentive aspects across three dimensions of practices: bodies, objects and social contexts [66,51]. By putting forward agency-and not agents-at the center of analysis, rational choice and individual attitudes are minimized. Inasmuch as rational choice theories have conquered a stronghold in the wider consumption studies field, they have failed to take proper account of social and material contexts. Indeed, in the "praxeological family of theories" [46] where we can include practice theory, action should be considered a "conglomerate of many surprising sets of agencies" rather than being fully controlled by consciousness [32,p. 44].

\subsection{Bodies and embodied skills}

As mentioned above, the body is one of these sets of agencies. In this perspective, the traditional Cartesian distinction between mind and body is supplanted by a conception of an indissoluble mind-body that is immersed in particular social and material environments. According to the anthropologist Ingold [29], the relationships experienced by agents within these environments become embodied as capacities of awareness and response, or skills. The fact that these skills can be considered embodied dispositions for action has similarities with Bourdieu's concept of habitus. As Bourdieu [6,7] states, lived experiences inscribe habitus 
into bodies, and these habitus constitute schemes of perception, thought and action, which orientate practices. It is important to note that habitus guarantees the conformity of practices performed by individuals with collective processes. However, at the same time, these performances are not just mere implementations of social models and norms, since particular life experiences and different situations allow for adaptation and individual creativity. Habitus can thus be understood as a "socialized biological body" [7]. That is, a "kind of practical mastery" acquired by "routinely carrying out specific tasks involving characteristic postures and gestures", which is what Ingold [29,p. 162] associates with skill. Thus, through experience and training in the performance of particular activities, skills are incorporated into human bodies [29]. Bodies become "repositories of experiences", unique forms of knowledge which affect the ways people adapt to new experiences and consume [61]. In sum, in this view, life experiences and routines are ways of acquiring competences, understandings and dispositions which are embedded both in body and mind and influence individuals' capacity to act.

Literature on the use of information and communication technologies has provided a good empirical illustration of this perspective. As pointed out by Christensen and Ropke [12,p. 241], computer use is a "mental-bodily routinized practice" that, once learned through training, allows the user to apply the same competences and understandings in other situations, such as using mobile phones, DVD players, or withdrawing money from cash dispensers. Thus, we can say that through experience and habit most people have incorporated skills that are shared with other practices requiring similar mental-bodily gestures and logics (ways of doing and thinking). These dispositions can facilitate (or not) adaptation to new technologies, as when people who have learned to master the computer mouse and physical keyboards start using touchscreens in smartphones or other devices.

\subsection{Objects and material contexts}

Besides illustrating the relevance of embodied skills, the examples above also show how objects are closely related to (or even integrated in) bodily-mental routines. Indeed, as previously mentioned, technologies and material contexts are another set of agencies forming practices. Or, as put by Shove et al. [56], things and materials have a constitutive role in everyday life. This conception shares insights with science and technology studies, within which literature on the agency of non-humans has been further developed. Far from adopting a deterministic point of view on the influence of technology over society, practice theory focus on how objects participate in the continual configuration of practices. As illustrated by Latour [32,p. 77], the practice of being a "couch potato" in front of a television set has been "permitted by the TV command" which allows the viewer to surf from channel to channel despite his immobility. Objects are thus "bearers of predispositions for consumption" [66,p. 66]. This perspective has benefited from Akrich's [2] concept of script . As she argues, technologies can prescribe or permit certain relationships between users and objects through a process of "inscribing" programs of action in the object. In this process, designers try to embed in the object their visions of future users' skills, purposes and understandings. However, as observed by Akrich, processes of "description" also occur, in the sense that real users are active agents in shaping their relationships with objects. In tune with the development of technology studies, which underline users' active appropriation of technologies, it can be said that, by bringing their embodied habits and experiences to how they use technologies, individuals can reject those scripts and use objects in unexpected ways which differ from the ones intended by designers.
Objects are not isolated from material contexts. The development of domestication theory has shown the complexity of relationships with the objects within the socio-technical contexts of households in everyday life. From this point of view, new technologies are like wild animals that have to be "housetrained" or, in other words, "integrated into the structures, daily routines and values of users and their environments" in order to become part of the family [4,p. 2]. This perspective highlights the process of integrating artifacts into settings and associating them with practices, people and other things [58]. In sum, both objects and the socio-technical context in which they are used have the capacity to influence practices.

There is evidence of this agency in the literature, for example about how the economic context contributed to the popularization of the mobile phone among adolescents. As observed by Ling and Yttri [36], a key element in the adoption of mobile phones by teenagers has been the pre-paid card system. Due to the high cost of phone calls, the pre-paid card afforded parents the possibility of avoiding large bills, since the calls are paid for beforehand and, after that amount is spent, the phone only allows calls or messages to be received. Furthermore, as SMS text messages are usually cheaper than phone calls, teenagers have been induced to use them more-and have become users to an extent that had not been foreseen by designers [9].

Moreover, the agency of material contexts is manifest if we consider that mobile phones are dependent on wireless networks, as well as interdependent with other mobile phones, to such a high degree that these interactions strongly influence the experience of users and eventually practices: for example a reliable and high quality signal transmission can provide a satisfying feeling and thus support the habit of long phone calls or, in the opposite situation, induce the use of other means of communication. The expansion of the Wi-Fi infrastructure also encourages the use of web browsing and social networking through mobile phones.

\subsection{Socio-cultural contexts}

The third dimension of distributed agency we address concerns socio-cultural contexts. According to Sahakian and Wilhite [51], this dimension includes settings, norms, values and institutions. Changes in these elements may also influence shifts in practices. Indeed, as shown by Shove and Pantzar [55] the history of the practice of (recreational) walking is strongly connected to the institutionalization of leisure, to conventions and ideologies related to nature, freedom, wellbeing and health, as well as to marketing. Furthermore, these conditions vary between different cultural and social settings. Thus, attention needs to be paid to the "creation of norms, standards and institutions which produce shared understandings and common procedures" [64,p. 295]. From our point of view, this dimension refers to the shared layer of knowledge (or cognitive-symbolic structures) which, according to Reckwitz [46,p. 246], enables a symbolic organization of reality by laying down "which desires are regarded as desirable and which norms are considered to be legitimate". These shared structures of knowledge seem to provide the framework for and formulate the conventions and expectations regarding what can be considered a "normal" practice [54].

A good illustration of this was provided by Pantzar [42] study of the diffusion process of the mobile phone in Finland. In order for this technology to be adopted as a normal object in everyday life, the use of the mobile phone had to be embedded within the values and norms of that specific socio-cultural context. As it spread, and through the accumulation of user experience, it came to be seen as a useful tool, not just as a toy or a fashionable gadget. Hence, as Pantzar observed, the use of the mobile phone became culturally stabilized and a socially accepted need. Norms, values and ways 
of organizing everyday life such as the extension of the possibility of making social contact, expanding occasions for interaction with family and friends, micro-coordinating interactions in real time [36], reproducing feelings of "closeness" or "connected presence" in relationships [33,10], asserting autonomy [9], and even providing a sense of security [34], seem to have been decisive in the normalization of the mobile phone use in everyday life. As observed by Sorensen [58], with the diffusion of the mobile phone in Norway, access to it became pressing. Furthermore, the feeling of belonging or being part of a group urges users always to carry the mobile phone with them and to have it turned on, and thus, "over time, a collective domestication produces new norms and expectations that influence the way the artifact is used, the meaning it signifies, and the possibilities of learning new ways of doing and thinking about it" [58,p. 56].

\subsection{Distributed agency and change in practices dependent on energy consumption}

The concept of distributed agency may help to understand how practices emerge, stabilize, change and eventually disappear. As shown in the literature above mentioned, the agency of these three dimensions contributes to the continual configuration of practices. To be sure, from the standpoint of practice theory, agency is not understood as resulting from individual rational choice and interests, nor the outcome of social structures. As pointed out by Giddens, action is both shaped and enabled by social structures, and these depend on their reproduction through human action; hence, practices depend on forms of practical knowledge guided by structural features like rules and resources ([19]; cit. in [56]). In practice theory, individuals (or practitioners) are therefore understood as carriers of practices $[46,56]$. The analysis of the dynamic interconnections between the elements that integrate practices enables to understand how these change i.e., are formed, reproduced and dissolved [43].

From our point of view, understanding how these different dimensions form practices contributes to envisaging how energy consumption is embedded in everyday life. However, energy consumption, or the consumption of other resources (e.g., water or raw materials), can be understood as a means of accomplishing certain practices [63] or "an outcome" of performing practices [62], not as a practice itself. For example, posting messages to social media on a mobile phone implies consuming battery power. While posting messages or videos is an activity recognizable as a practice (according to Warde's [64] criteria for identifying practices), using the electricity required to accomplish that practice is not-despite practitioners' need to ensure its availability. Thus, watching videos on the mobile phone, for instance, implies taking on other activities, such as simply plugging in the phone to a power supply, or managing the battery's life by orchestrating competences such as turning off features and other services that drain its power. Therefore, we analyze the practices of charging and managing the power of mobile phones (inextricably interwoven with other co-dependent practices related to mobile phone use), and not simply of consuming energy through the use of mobile phones.

As argued by Gram-Hanssen [22], if energy consumption is considered part of several different practices, we should examine whether changes in parallel practices affect other practices which have similar elements (technologies, know-how or other). Therefore, considering that the bodily-mental activities involved in mobile phone battery management are a routinized practice similar to the use of different technologies which require the same competences and understandings, analyzing the routines, competences and understandings related to mobile phones battery management may shed light on a variety of practices that involve the use of batteries.

\section{Setting an empirical study of charging and managing mobile phone batteries}

Practice theories have been subject to criticism for a variety of reasons, a key issue being the fact that practices (and not individuals) should be considered the unit of analysis, which in turn raises the problem of defining the boundaries of a practice [64]. On the topic of the analysis of information and communication technologies based on a practice theory approach, Christensen and Ropke [12] noted the ambiguity in the delimitation of different practices that include these technologies. For example, the mobile phone can be used in a diversity of practices such as interacting with friends or playing games. In this article we focus particularly on battery charging and management. Thus, we analyze the interwoven activities carried out in order to guarantee mobile phones' power.

Results presented in this article are part of a research project on energy consumption related to teenagers' use of electronic media. Our project combines quantitative and qualitative methods, as this kind of mixed method approach provides insights for understanding the diversity of the performances analyzed both in extensive and in intensive forms. In line with this approach we carried out a survey and interviews with adolescents enrolled in three schools in Lisbon, Portugal. In order to guarantee a diversified sample, each school represents distinct socio-economic backgrounds. One of the schools is a regular secondary state-funded school (and thus the parents of the enrolled pupils have a variety of socio-economic statuses); a second state-funded school offers work-oriented/professional courses, with most students coming from lower income families; the third school is an elite private school, with most pupils belonging to well-off families.

Through the survey we collected data on themes such as the electronic media owned, the frequency, intensity, activities and places of electronic media use, and some doings related to the energy consumption of these devices. Students responded to this paper-and-pencil questionnaire during one class period, in the presence of one of the researchers. The survey was conducted between November 2014 and January 2015. The sample includes 748 students enrolled in the ninth to twelfth grade. In total $54 \%$ of respondents are boys and 46\% are girls. The average age is 16 .

The interviewees were recruited among the survey respondents. A higher number of girls were willing to participate and, therefore, only 8 out of 22 interviews were conducted with boys. Nine interviewees were enrolled at the regular school, nine at the private school, and four at the professional school. Themes covered included their daily routines of electronic media use, engagements with electronic media (meanings, attachment, peer and family pressures), competences in electronic media and energy consumption (knowledge, skills), and material environment (devices owned, access to related services and infrastructures). On average the interviews lasted $104 \mathrm{~min}$. These interviews took place between December 2014 and March 2015. After being fully transcribed, the interviews were subject to qualitative content analysis. The process of coding the interviews evolved from an initial set of categories corresponding to the themes explored, to a second coding aimed at identifying the contents related to bodies, objects, and sociocultural contexts. After that we re-analyzed the interviews looking for practices related to charging and managing mobile phones' power (third coding). The following categories were then identified: emergence of elementary battery use, acceleration of rhythm and establishment of links, and normalization. The findings presented here are based on the intersections observed between the second and third coding processes. 


\section{Practices of charging and managing the power of mobile phones}

In the following we observe diverse configurations in the relationships between bodies, objects and socio-cultural contexts. As the interconnections between these dimensions are redefined, practices of charging and managing the power of mobile phones emerge. In order to analyze how the configurations between these dimensions co-evolve, we look at the changes which have occurred in the (short) life course of adolescents.

\subsection{Emergence of elementary battery use}

Some studies indicate that parents tend to encourage the use of information and communication technologies by children as a way of favoring their opportunities in life [20,37,53]. Moreover, the use of the mobile phone in particular has been pointed out to be promoted by parents as a way of providing control [24], a sense of security [34], or closeness [10] in their relations with their children.

Data from our interviews with adolescents show that in many cases their first mobile phone was given to them on their parents' initiative, and not due to a request of their own. Furthermore, data from our survey show that the average age at which the first mobile phone was obtained was 10 years $(S D=2.08)$. This is precisely when children move from primary schools to the next level of education, which usually implies attending larger schools with less social control. Often there are also changes in their organization of everyday life, due to different school hours and their enrollment in after-school activities. These changes sometimes mean that children start commuting by themselves, or that they start needing to call their relatives to pick them up at the end of the day or to take them to after-school activities. The mobile phone then becomes a device that enters into children's everyday life with quite limited functionality-its use is mostly restricted to contacting children's parents. As Vítor ${ }^{1}$ told us, his first mobile phone was just meant to let his parents know where he was, and whether one of them was already waiting for the other when pick up arrangements were made.

In some cases, these mobile phones were not even owned by the children, but only lent to them for the time they were at school (so that they could use it "in case of emergency", as Olivia explained to us). In addition, the maintenance of the device was not expected to be ensured by the child. Thus even though the battery was already present as an object, the child was not required to develop any skill related to it.

The case of Daniela illustrates this process well. Her first mobile phone was given to her by her mother when she was seven years old. At the time she was only able to use it to call her mother-"I didn't know very well how to use it". She was not fully aware of the requirements of the object, as the mobile phone had not acquired much meaning for her yet, but she remembers her mother's concern about it:

"My mother used to say «Daniela, go and get the charger and plug it in. " Because I didn't even think about it. It was more important for her so that she could communicate with me, than for me. I didn't care about that, but she was always saying 'go get the charger, you have to charge your mobile phone so that I can contact with you tomorrow." (Daniela)

Thus, in the case of Daniela, she was asked to embody the action of charging her phone, but she was not expected to master that skill by herself. Although carrying out that task gave her training,

1 The names of the interviewees are aliases. she had not developed yet a full connection (i.e., a full mental-body disposition) with the object, as this connection was in fact mediated by her mother. Indeed, the relevance of using the mobile phone was still very limited and circumscribed to contacting her mother, and the device's need for energy was regulated by her mother.

In the case of Eduardo, charging his first mobile phone was straightforward. Although nobody else was regulating his mobile phone's power usage, his embodiment of the skill of charging the phone was elementary, involving only minimal bodily-mental activity: "it was just charging; I had no technique or anything to make it [the battery] last longer. (...) It was simple". In some cases, it was the object itself that requested to be charged, by beeping when its battery was running down. Thus, as Clara suggested, they did not need to have that on their minds.

When the adolescents of our study began having their first mobile phones, these devices were already present in their everyday lives. Many of their older family members owned one, and some of their schoolmates were also beginning to have their own. In this socio-cultural context, these objects were coming to be regarded as desirable, even though their use was very limited and had not been integrated with other practices such as contacting their friends or social networking. As Madalena told us, she asked for a mobile phone when she was around ten years old because some of her schoolmates already had one. But she "didn't even use it." "It was just to carry it with me. (...) It was just to say I had one."

Thus, despite the potential for agency of bodies, objects and socio-cultural contexts, the interconnections between them were not indeed established to the point of forming practices of charging and managing the power of mobile phones. The elements existed but had not yet been integrated [43]. In the following section we look at the process of creating links between these elements.

\subsection{Acceleration of rhythm and establishment of links}

Mobile phones have gone through significant changes in recent years. Since the introduction of the first smartphones, not just their physical characteristics (size, screens, keyboards) and operating systems (with increasing processing power, memory and features, functions and applications available) have changed significantly, batteries have also evolved. Batteries are now thinner, lighter, have higher capacity and take less time to charge. However, the increasing functionality of smartphones has taken a toll on battery power $[8,1,17]$. If older mobile phones could run for several days before they needed to be recharged, very often smartphones need daily charging.

Mobile telephony's material context has also changed considerably, as the development of wireless infrastructures has allowed for increasing speed and wider coverage. Most teenagers we interviewed have limited access to the internet on their mobile phones due to its high cost. This encourages them to rely on Wi-Fi networks, which are increasingly available in public spaces, such as commercial centers, public transport, and so forth. The material context of schools has also evolved. Following a government decision, since early 2006 all public schools in Portugal offer free wireless broadband access to the internet. Despite some complaints regarding speed, this infrastructure strengthened adolescents' mobile phone use throughout the day, and even during classes, regardless of schools' regulations forbidding uses not related to classes. In fact, $90.4 \%$ of our survey respondents said that they use their mobile phones at school, nearly as much as at home (90.7\%).

Moreover, inasmuch as mobile phones have a diversity of features common to other information and communication technologies, such as the ability to play music and video, cameras, games, access to the internet, instant messaging, email, and even word processing and spreadsheet facilities, the relationships of these devices with other technologies have also changed. On the 
one hand, similarities between technologies (also regarding battery use) allow for transfers of embodied skills and know-how. On the other hand, the increasing mobility of mobile phones due to the expansion of wireless infrastructures, together with their growing multi-functionality, make these devices a pervasive "must have" or an "addiction", as sometimes mentioned in the interviews. Several adolescents told us that they even prefer using their smartphone instead of the computer, as the smartphone is faster and more practical.

"With the mobile phone I can be in contact with people, and it's not so much because of social networks, (.. .) but also because now that I have a smartphone, and there are applications for everything. . It also helps with school work (...). The mobile phone basically helps me with everything. If I need some help, if I need to be reminded of something to do, if I need to talk to someone, I use the phone." (Bruno)

Thus, the agency of both objects and material context become visible. As the multi-functionality of smartphones, together with their high portability, make them indispensable objects, the rhythm of their use is accelerated. Temporal patterns of non-use are now shorter. Indeed, the owners of older mobile phones attribute their lack of engagement with these devices to the fact that they do not have the features of newer mobile phones. The case of António, who owns an outdated mobile phone, illustrates this. He admitted that his device is not very important to him because it is not a smartphone. If it was, he believes he would use it more. As it is not, he relies on the computer and the television more than other interviewees. Thus the new features of smartphones contribute to accelerating the rhythm of use.

In order for this acceleration to happen, links need to be established between object and body. As several interviewees told us, since they have a smartphone, they have developed new habits. This includes the admittedly "annoying" (Cristiano) habit of checking their phone over and over again, even knowing that nothing has happened, and there is no message, as the device has not signaled any notification. As Cristiano told us, "everyone" who uses a smartphone developed this habit of handling their smartphones: they (himself included) take it, unlock it, and look at it, as the expectation of something happening is an overriding feeling. As he explained, the device "has so many things", that "one is always expecting something new, especially when one has access to the internet". These embodied skills or dispositions for action are not merely body habits. As Júlia told us, when she does not have her mobile phone with her, she cannot receive information, notifications or invitations, and that makes her feel "excluded". As Júlia admitted, it bothers her not to have her mobile phone in her pocket: "I guess it is an addiction." And as one other girl tried to explain, the habit of having and using her mobile phone is so entangled with her body that, when she does not have it next to her, she just "feels" its absence:

“When I don't have my mobile phone, if I forget it, I feel it, because it's almost as if I didn't have something next to me, and then. . . it's a feeling. . . as it's always close to me, when it isn't in the pocket it's a feeling and then I remember." (Diana)

Thus, the feeling of a need to have the mobile phone always available becomes embodied. This embodiment is visible in other ways. Several interviewees described how they take care in order to keep their mobile phones always close to them, whether in their pockets or in their bags, wherever they go (sometimes even when they take a shower), and also their strategies to never forget it (such as putting it on the bed while they are getting dressed in the morning to make it more visible). To pick it up and to carry it with them "is that automatic thing" as Daniela explains. Some of them also admit to going back home to pick it up if they happen to forget it on the way out-even if they are running late.

Furthermore, the socio-cultural context has also changed. Now there are clear norms regarding what is a desirable mobile phone, and what is not. A girl we interviewed illustrated this well when she admitted that her dream was to own an iPhone, because that is the mobile phone "everyone wants to have". On the contrary, having a mobile phone like the one of António's is often criticized by the peer group-older models of mobile phones are referred to as being "rotten" or "from the Stone Age". Hence, the socio-cultural context shapes mobile phone use by pressuring adolescents toward demonstrating their conformity with shared values and norms. On the one hand, that is the case for owning certain types of mobile phones, such as the latest smartphones, especially from the leading brands. Indeed, as observed by Gram-Hanssen [20], mobile phones seem to be highly loaded with status and symbols, and teenagers with "embarrassing" mobile phones use them less frequently. On the other hand, another kind of peer pressure observed shapes the display of a desirable youthful lifestyle. Due to their multifunctionality and portability, mobile phones are a valuable object for that purpose. Their ability to photograph and record videos, and to immediately upload them through social networking applications, provide the possibility to show (and prove) attendance at a music festival, the tasting of a delicacy or even the most banal (non-) events. The need to continually feed social media assumes therefore intensive use of these devices. Our interviewees described (often with a critical slant) many performances enacted by teenagers through the use of mobile phones in order to be considered "social" or popular, such as intensively taking pictures of themselves (selfies) and immediately posting them on social media like Facebook or Instagram. In a different way, the socio-cultural context also pressures them toward displaying intensive use of mobile phones, as this is connoted with having many friends to talk to. Indeed, the high number of SMS text messages reported in our survey to be sent every day suggests some respondents might have overestimated that, as in some cases they indicated several hundreds. ${ }^{2}$

These findings show how the co-evolution of these diverse agencies establishes links between the features of the object (smartphone), its material surroundings (wireless infrastructure), the users' bodies (embodied habits) and the socio-cultural context (norms, values). Intensified mobile phone use fits everyday life's temporal patterns (e.g., waking up and getting ready to go to school, commuting, classes and breaks as well as different weekday/weekend uses) and spaces (e.g., home, school). However, temporal and spatial patterns of mobile phone use need to be synchronized with (shorter) battery life cycles. Therefore, battery power needs to be orchestrated in accordance with multiple circumstances, since in order to accomplish this acceleration of rhythm, charging up the phone's battery and managing its power becomes a key performance issue. Practices of battery management emerge.

\subsection{Normalization}

As the use of the mobile phone accelerates its rhythm and those three dimensions are actively interconnected, we may observe the formation of practices of charging and managing the power of mobile phones. Smartphone's features such as touchscreen displays, multiple network connections, location technologies and operating systems significantly increase their energy consumption compared to less sophisticated mobile phones. This demand

\footnotetext{
2 Due to a great dispersion of results, we consider the median instead of the mean: thus, half of respondents said that they send 50 or less SMS messages every day. The highest frequency (mode) is 100 SMS sent every day.
} 
Table 1

Management of mobile phone features or functions in order to make the battery last longer $(n=748){ }^{6}$

\begin{tabular}{ll}
\hline Frequency & $\%$ \\
\hline Always & 30.7 \\
Very frequently & 22.8 \\
Frequently & 18.6 \\
Not frequently & 12.1 \\
Rarely & 7.4 \\
Never & 8.4 \\
\hline
\end{tabular}

for power is increased by the fact that many applications require an internet connection. Smartphones are thus "power-hungry devices" [1]. However, their functioning depends on batteries with limited capacities. The battery power is therefore a "fundamental and highly constrained resource" and "one of the most remarkable" constraints affecting the use of these devices [17]. As put by Carroll and Heiser [8,p.1], the smartphone's "rich functionality increases the pressure on battery lifetime, and deepens the need for effective energy management."

Our interviewees, especially those who use smartphones, are well aware of this power hunger, and of the fact that these devices need to be fed in order to stay "alive". Interestingly, to say that a phone "dies" when its battery runs out is a common expression. And like a living organism, the mobile phone (especially when it is "smart") is always consuming power, even when idle.

“These mobile phones [smartphones]. . . even if I don't use it now, it is draining, because it has the apps running, it is always active and receiving things. .." (Clara)

Given the pervasiveness of mobile phones in adolescents' everyday lives, and the fact that they integrate several of their everyday practices (e.g., social networking, web browsing, communicating with family and friends), ensuring fully charged batteries becomes a need. This turns into a routine, and at the same time battery management skills become embodied. In fact, survey results suggest that most teenagers in this study have some embodied routines of managing their mobile phone's features or functions in order to make the battery last longer, as $53.5 \%$ say that they always or very frequently do this. Whilst $8.4 \%$ say that they never do it, we should note that this includes the number of respondents (3.1\%) reporting not using a mobile phone (see Table 1 ).

Bruno's case is a good illustration of how this practice of charging and managing the power of the mobile phone is indeed a bodily-mental performance. He explained that his concern about the battery induces him to regularly check its remaining power; based on that and on what he expects to do throughout the day until he arrives home (where he can charge his battery), he calculates how he should use his phone in order always to have battery power.

"I usually manage my battery. I have a concern, so to speak, about my battery. I see the amount of battery I have left. For instance, I have $70 \%$ and I think what am I going to do from now on (...) until I get home... (...) and I think "this is enough to use the rest of the day» or "I only have 30\%», (...) [if] I don't want to spend more than $10 \%$, I get to $10 \%$ and I stop. Then I proceed more or less as if. . . well, I make an estimation and see... (...) If I have 30\% power, I don't need any of that [listening to music whilst walking], man, I'll save a bit of power, and won't listen to music for a while, there's no harm in that. . I'm always checking my battery for what I need, and I never got home with less than $20 \%$ of power on my phone." (Bruno)

\footnotetext{
${ }^{6} \mathrm{M}=4.32, \mathrm{SD}=1.59$ ( 1 = never; 6 = always $)$
}

Besides the curtailment acts mentioned in this quote, diverse other activities correspond to battery management skills, such as turning off functions and features when they are not necessary. For example, several interviewees said that they turn on the "flight mode" (although using this function in a way different than that intended by the designers) when they are seeking to extend the power of their batteries. By switching off their network connections, this certainly saves power. However, the mobile phone is programmed to operate with all its features, and unless the user remembers to turn them off, they remain active.

"When I'm not using it [Wi-Fi] I turn it off. What happens is, when I'm at school I turn it on because I know I have internet, but [later] when I realize that it is on, and hadn't seen it, I turn it off." (Daniela)

Adding to these skills, some interviewees refer to applications or features integrated in mobile phones that allow power saving, such as an "eco mode" that lowers screen brightness and turns off Wi-Fi connections, or an application that according to Bruno cuts off the power supply from the socket when the battery is charged.

"I have an app that controls that, when it reaches $100 \%$ overcharges for two minutes and then that app cuts the connection between the mobile phone and the charger and it doesn't charge anymore. That is very convenient to me because this way I can charge it during the night; after I have drained the battery throughout the day, I go to sleep (...) and I charge it (...)." (Bruno)

As managing the power of their mobile phones becomes a widespread practice and an embodied habit, finding themselves deprived of using their mobile phones because they ran out of power is not a frequent situation. Actually, according to our survey findings, $21.5 \%$ say they are very often in this situation, while $35.9 \%$ claim that this "never" or "rarely" happens to them $(\mathrm{M}=3.24$, $\mathrm{SD}=1.44) .^{3}$ Girls might be less skilled in managing battery power, as their mobile phones more often run out of power $(M=3.37$; $\mathrm{SD}=1.44)$ compared to boys $(\mathrm{M}=3.13 ; \mathrm{SD}=1.42) .{ }^{4}$ To avoid this situation, many of them charge their mobile phones seven days a week $(M=6.39$; $S D=5.22)$. Indeed, many interviewees told us that they charge it overnight, while they are asleep. Again, girls charge their mobile phone batteries more often $(M=6.51 ; S D=3.45)$ than boys $(\mathrm{M}=5.74 ; \mathrm{SD}=3.08) .^{5}$

These practices are not necessarily oriented to energy efficiency. For example, Raquel explained that sometimes she uses her computer instead of the mobile phone to avoid "draining the battery" of the latter. Filipa showed that she is only concerned about ensuring the functionality of her mobile phone:

"Sometimes I like to use the mobile phone while it's charging up. Because this way I'm not running down the battery!" (Filipa)

Furthermore, as Barbara told us, some smartphones' batteries "are meant to not last long"-only one day. This points to another form of material agency-the fact that batteries become less efficient over time. This encourages performances which prevent batteries wearing out, as almost always this implies the replacement of the mobile phone.

“(...) before buying I talked with my father about the mobile phone and he told me that to prevent iPhones' batteries wearing out they have to fully discharge, run all the way down; otherwise the battery will become worn out. So I always did that: use it until it runs out and then fully charge it." (Bárbara)

\footnotetext{
3 The response scale of these questions varies between 1 (never) and 6 (always).

4 This difference is statistically significant $(t(737)=2.30 ; p<.05)$.

5 This difference is statistically significant $(t(718)=3.204 ; p<.05)$.
} 
However, most times these practices do not seem to be based on well-grounded, formal knowledge, but on practical knowledge and processes of informal learning, as many do not "waste time searching" (Daniela) for information on battery management. And often "myths" or jokes circulate among adolescents. As Júlia told us, sometimes her friends suggest either to try to put the battery in the freezer or to warm it up in order to make it last longer.

\section{Conclusion}

This analysis shows the emergence and normalization of practices of charging and managing the power of mobile phones among adolescents. At an early stage, despite the fact that mobile phones are already present in their everyday lives, their bodily-mental skills regarding the use of these devices (and, more importantly, their power consumption) are elementary. There is already a sociocultural context favorable to the use of mobile phones, but bodies, objects and socio-cultural context are not sufficiently interwoven.

Data show that when most interviewees begin using a smartphone, there is a process of acceleration of their rhythm of mobile phone and battery use. Several elements converge and flow into the establishment of interconnections between bodies, objects and socio-cultural context. Thus the need to orchestrate battery power together with these different agencies leads to the formation of practices of charging and managing the power of mobile phones.

The process of normalization (and reproduction) of these practices then allows the successful integration of mobile phones into everyday life. Indeed when these practices do not become normal, tension and disruption can emerge. As when the mobile phone needs to be recharged earlier than expected or a charger is not available, co-dependent practices may be affected or thwarted.

Practices of charging and managing battery power include techniques that enhance energy efficiency (such as lowering unnecessary screen brightness), curtailment measures (such as not listening to music) or actions that do not save any energy (simply charging the battery sooner, even if it has substantial energy left, or using another device, like an MP3 player). It is particularly clear that girls get into the habit of charging the battery overnight more easily than learning how to manage battery power more efficiently. Thus, the normalization of these practices does not necessarily bring a positive outlook toward the transition to a sustainable energy system. Practices of charging and managing battery power are instrumental in securing the functioning of an object which is key for performing other meaningful co-dependent practices (e.g., social networking), but not meant to reduce energy consumption. As these practices are mostly oriented toward securing the services desired, adolescents are not necessarily incorporating skills and dispositions toward energy efficiency.

Furthermore, it is very likely that the proliferation of technologies using batteries in everyday life will continue to increase in the future. Without changes in the interconnections between bodies, objects and socio-cultural contexts it is unlikely that the transfer of these practices to other technologies will result in higher energy efficiency. In fact, as this study shows, these interconnections have been co-evolving in ways that enhance continuous use and intensified integration of digital technologies into everyday life and, therefore, more energy consumption.

However, as observed by Christensen et al. [11], although teenagers' awareness of energy consumption associated with the use of information and communication technologies is quite limited, their experiences with mobile devices provide them practical knowledge about the electricity consumption of these devices. Thus there is a possibility that under some circumstances these practices might provide power management skills applicable to the use of other technologies. In any case, as the "practical mastery" [29] of managing battery power is mainly acquired through the experience of mobile phone handling, energy efficiency might be promoted when designing these objects by making power management more intuitive and easy to use.

A previous study showed that Portuguese teenagers are not proactive regarding energy saving, especially when it is related to digital technologies due to their importance in their everyday life [53]. This is in line with what has been observed in other European countries [11] and we surmise that it may not be much different from other urban contemporary societies. However, we should bear in mind the specificity of this life stage. It would be worth carrying out further studies on what happens to these practices' careers when these practitioners get older and they build new links in their lives between practices and their inner elements.

\section{Acknowledgments}

The authors are very grateful to Kirsten Gram-Hanssen, the editors of this special issue, and two anonymous reviewers for their valuable comments and generous suggestions. The results presented are part of a research project developed with the support of the Institute of Social Sciences, University of Lisbon, and funded by the Portuguese Foundation for Science and Technology under the award EXPL/IVC-SOC/2340/2013.

\section{References}

[1] A. Abdelmotalib, Z. Wu, Power consumption in smartphones (hardware behaviourism), Int. J. Comput. Sci. Issues 9 (3) (2012) 161-164.

[2] M. Akrich, The de-scription of technical objects, in: W. Bijker, J. Law (Eds.) Shaping Technology/Building Society, MIT Press, Cambridge, 1992.

[3] N. Banerjee, A. Rahmati, M. Corner, S. Rollins, L. Zhong, et al., Users and batteries: interactions and adaptive energy management in mobile systems, in: J. Krumm (Ed.), UbiComp 2007 Ubiquitous Computing, Springer-Verlag Berlin Heidelberg, Berlin, 2007, pp. 217-234.

[4] T. Berker, M. Hartmann, Y. Punie, K. Ward, Introduction, in: T. Berker, Y. Hartmann, K. Ward (Eds.), Domestication of Media and Technology, Open University Press, New York, 2006, pp. 1-17

[5] P. Bourdieu, Outline of a Theory of Practice, Cambridge University Press, Cambridge, 1977.

[6] P. Bourdieu, Le Sens Pratique, Minuit, Paris, 1980.

[7] P. Bourdieu, Meditações Pascalianas, Celta, Oeiras, 1998.

[8] A. Carroll, G. Heiser, An analysis of power consumption in a smartphone, USENIXTAC'10 Proceedings of the 2010 USENIX annual technical conference (2010)

[9] M. Castells, M. Fernández-Ardèvol, J.L. Qiu, A. Sey, Mobile Communication and Society: A Global Perspective, MIT Press, Cambridge, 2007.

[10] T.H. Christensen, 'Connected presence' in distributed family life, New Media Soc. 11 (3) (2009) 433-451.

[11] T.H. Christensen, R. Mourik, S. Breukers, T. Mathijsen, H. Heuve, Young people ICT and energy-status and trends in young people's use and understanding of ICT and energy consumption: D2.1 Technical report on the organization and outcomes of focus groups and the mapping exercise, Intelligent Energy Eur. (2014).

[12] T.H. Christensen, I. Ropke, Can practice theory inspire studies of ICTs in everyday life? in: B. Brauchler, J. Postill (Eds.), Theorising Media and Practice, Berghahn Books, New York, 2010, pp. 233-256.

[13] M. Coleman, N. Brown, A. Wright, S.K. Firth, Information, communication and entertainment appliance use-insights from a UK household study Energy Buildings 54 (2012) 61-72.

[14] F. Colombo, L. Fortunati (Eds.), Broadband Society and Generational Changes, vol. 5, Peter Lang., Frankfurt, 2011.

[15] T. Crosbie, Household energy consumption and consumer electronics: the case of television, Energy Policy 36 (2008) 2191-2199.

[16] A. Fehske, J. Malmodin, G. Biczók, The global footprint of mobile communications: the ecological and economic perspective, IEEE Communications Magazine 2011 (August) (2011) 55-62.

[17] M. Ferroni, A. Cazzola, F. Trovò, D. Sciuto, M.D. Santambroglio, On power and energy consumption modeling for smart mobile devices, in: Proceedings of the 12th IEEE International Conference on Embedded and Ubiquitous Computing (EUC), IEEE, 2014, pp. 273-280.

[18] D.K. Forgays, I. Hyman, J. Schreiber, Texting everywhere for everything: gender and age differences in cell phone etiquette and use, Comput. Hum. Behav. 32 (2014) 314-321.

[19] A. Giddens, The Constitution of Society, Polity Press, Cambridge, 1984

[20] K. Gram-Hanssen, Teenage consumption of information and communication technology, ECEEE 2005 Proceedings. European Council for an Energy Efficient Economy (2005). 
[21] K. Gram-Hanssen, Standby consumption in households analyzed with a practice theory approach, J. Ind. Ecol. 14 (1) (2009) 150-165.

[22] K. Gram-Hanssen, Understanding change and continuity in residential energy consumption, J. Consum. Cult. 11 (1) (2011) 61-78.

[23] J. Gronow, A. Warde, Introduction, in: J. Gronow, A. Warde (Eds.), Ordinary Consumption, Routledge, London, 2001, pp. 1-8.

[24] L. Haddon, Social media and youth, in: R. Mansell, P.H. Ang (Eds.), The International Encyclopedia of Digital Communication and Society, John Willey \& Sons, 2015, pp. 1-9.

[25] M. Heikkinen, J. Nurminen, Measuring and modeling mobile phone charger energy consumption and environmental impact, Proceedings IEEE Wireless Communications and Networking Conference: Services, Application, and Business (2012) 3194-3198

[26] M. Heikkinen, J. Nurminen, T. Smura, H. Hammainen, Energy efficiency of mobile handsets: measuring user attitudes and behavior, Telemat. Inform. 29 (2012) 387-399

[27] A. Horta, H. Wilhite, L. Schmidt, F. Bartiaux, Socio-technical and cultural approaches to energy consumption: an introduction, Nat. Cult. 9 (2) (2014) $115-121$.

[28] IEA, Gadgets and Gigawats Policies for Energy Efficient Electronics, International Energy Agency, Paris, 2009.

[29] T. Ingold, The Perception of the Environment, Routledge, London, 2000.

30] ITU, Mobile-broadband uptake continues to grow at double-digit rates. International Telecommunications Union. Available online at: http://www. itu.int/en/ITU-D/Statistics/Documents/facts/ICTFactsFigures2014-e.pdf 2014

[31] J.O. Jensen, K. Gram-Hanssen, I. Ropke, T.H. Christensen, Households' use of information and communication technologies-a future challenge for energy savings? ECEEE 2009 Summer Study-Act! Innovate! Deliver! Reducing energy demand sustainably. Available online at: http://vbn.aau.dk/files/ 75300895/ICT_ECEEE_2009_paper.pdf.</doc_ref $>2009$.

[32] B. Latour, Reassembling the Social. An introduction to Actor-Network-Theory, Oxford University Press, Oxford, 2005.

[33] C. Licoppe, 'Connected' presence: the emergence of a new repertoire for managing social relationships in a changing communication technoscape, Environ. Plann. D Soc. Space 22 (2004) 135-156.

[34] R. Ling, The Mobile Connection: The Cell Phone's Impact on Society, Elsevier, San Francisco, 2004

[35] R. Ling, Children, youth and mobile communication, J. Children Media 1 (1) (2007) 60-67.

[36] R. Ling, B. Yttri, Hyper-coordination via mobile phones in Norway, in: J. Katz, Aakhus, M (Eds.), Perpetual Contact: Mobile Communication, Private Talk, Public Performance, Cambridge University Press, Cambridge, 2002.

37] S. in:Livingstone, L. Haddon (Eds.), Kids Online: Opportunities and Risks for Children, The Policy Press, Bristol, 2009.

[38] G. Mascheroni, A. Cuman, Net Children Go Mobile: Final Report, Educatt, Milano, 2014, Deliverables D6.4 \& D5.2.

[39] Ofcom, Children and Parents: Media Use and Attitudes Report Ofcom (2014). Available online at: http://stakeholders.ofcom.org.uk/binaries/research/ media-literacy/media-use-attitudes-14/Childrens_2014_Report.pdf.

[40] S. Ortner, Thick resistance: death and the cultural construction of agency in Hymalaya mountaineering, in: S. Ortner (Ed.), The fate of Culture: Geertz and Beyond, University of California Press, Berkeley, 1999, pp. 136-165.

[41] A. Paiano, G. Lagioia, A. Cataldo, A critical analysis of the sustainability of mobile phone use, Resour. Conserv. Recy. 73 (2013) 162-171.

[42] M. Pantzar, Tools or toys-inventing the need for domestic appliances in postwar and postmodern Finland, J. Advertising 32 (1) (2003) 83-93.

[43] M. Pantzar, E. Shove, Understanding innovation in practice: a discussion of the production and re-production of Nordic walking, Technol. Anal. Strateg. Manage. 22 (4) (2010) 447-461.
[44] S. Pink, K.L. Mackley, Saturated and situated expanding the meaning of media in the routines of everyday life, Media Cult. Soc. 35 (6) (2013) 677-691.

[45] A. Rahmati, L. Zhong, Human-battery interaction on mobile phones, Pervasive Mob. Comput. 5 (2009) 465-477.

[46] A. Reckwitz, Toward a theory of social practices:a development in culturalist theorizing, Eur. J. Soc. Theory 5 (2) (2002) 243-263.

[47] I. Ropke, The unsustainable directionality of innovation-the example of the broadband transition, Res. Policy 41 (2012) 1631-1642.

[48] I. Ropke, T.H. Christensen, J.O. Jensen, Information and communication technologies-a new round of household electrification, Energy Policy 38 (2010) 1764-1773.

[49] I. Ropke, T.H. Christensen, Energy impacts of ICT-insights from an everyday life perspective, Telemat. Inform. 29 (2012) 348-361.

[50] I. Ropke, T.H. Christensen, Transitions in the wrong direction digita technologies and daily life, in: E. Shove, N. Spurling (Eds.), Sustainable Practices. Social Theory and Climate Change, Routledge, Oxon, 2013.

[51] M. Sahakian, H. Wilhite, Making practice theory practicable: towards more sustainable forms of consumption, J. Consum. Cult. 14 (1) (2014) 25-44.

[52] T. Schatzki, Social Practices: A Wittgensteinian Approach to Human Activity and the Social, Cambridge University Press, Cambridge, 1996.

[53] L. Schmidt, A. Horta, A. Correia, S. Fonseca, Generational gaps and paradoxes regarding energy consumption and saving, Nat. Cult. 9 (2) (2014) 183-203.

[54] E. Shove, Comfort, Cleanliness and Convenience: The Social Organisation of Normality, Berg, Oxford and New York, 2003.

[55] E. Shove, M. Pantzar, Consumers, producers and practices. Understanding the invention and reinvention of Nordic walking, J. Consum. Cult. 5 (1) (2005) 43-64.

[56] E. Shove, M. Pantzar, M. Watson, The Dynamics of Social Practice. Everyday Life and How it Changes, Sage, London, 2012

[57] E. Shove, G. Walker, What is energy for? Social practice and energy demand, Theory Cult. Soc. 31 (5) (2014) 41-58

[58] K. Sorensen, Domestication: the enactment of technology, in: T. Berker, Y. Hartmann, K. Ward (Eds.), Domestication of Media and Technology, Open University Press, New York, 2006, pp. 40-61.

[59] J. Suckling, J. Lee, Redefining scope: the true environmental impact of smartphones? Int. J. Life Cycle Ass. 20 (2015) 1181-1196.

[60] E. Thulin, B. Vilhelmson, Mobiles everywhere. Youth, the mobile phone, and changes in everyday life, Young 15 (3) (2007) 235-253.

[61] G. Wallenborn, H. Wilhite, Rethinking embodied knowledge and household consumption, Energy Res. Soc. Sci. 1 (2014) 56-64.

[62] G. Walker, The dynamics of energy demand: change, rhythm and synchronicity, Energy Res. Soc. Sci. 1 (1) (2014) 49-55.

[63] A. Warde, Consumption and theories of practice, J. Consum. Cult. 5 (2) (2005) $131-153$.

[64] A. Warde, After taste: culture, consumption and theories of practice J.Consum. Cult. 14 (3) (2014) 279-303.

[65] H. Wilhite, New thinking on the agentive relationship between end-use technologies and energy-using practices, Energy Efficiency 1 (2008) 121-130.

[66] H. Wilhite, Energy consumption as cultural practice: implications for theory and policy of sustainable energy use, in: S. Strauss, S.T. Rupp Love (Eds.), Cultures of Energy: Power, practices, technologies, Left Coast Press, Walnut Crek, 2013, pp. 60-72.

[67] H. Wilhite, Nakagami Hidetoshi, Takashi Masuda, Yukiko Yamaga, Hiroshi Haneda, A cross-cultural analysis of household energy-use behavior in Japan and Norway, Energy Policy 24 (9) (1996) 795-803.

[68] J. Yu, E. Williams, M. Ju, Analysis of material and energy consumption of mobile phones in China, Energy Policy 38 (2010) 4135-4141. 